\title{
BARDOS, PENAS E ARMAS: A PRODUÇÃO LITERÁRIA NA IMPRENSA AFRO-BRASILEIRA
}

http://dx.doi.org/10.11606/issn.2237-1184.v0i32p148-170

\author{
Petrônio Domingues ${ }^{\mathrm{I}}$ \\ Ruan Levy Andrade Reis ${ }^{\mathrm{II}}$
}

\begin{abstract}
RESUMO
Diversos jornais da imprensa afro-brasileira se autodenominavam "órgãos literários" e traziam em suas páginas contos, crônicas, poemas e até romances. $\mathrm{O}$ presente artigo tem a finalidade de investigar os textos literários publicados na imprensa negra de São Paulo entre 1915 e 1931, centrando-se na produção poética. O principal argumento é de que os intelectuais negros se valeram da poesia pelo sentido político, como meio de valorização da "classe dos homens de cor", contudo procuraram, na medida do possível, não negligenciar o seu sentido estético.
\end{abstract}

\section{ABSTRACT}

Several Afro-Brazilian newspapers use to call themselves "literary organs" and bring tales, chronicles, poems and even novels on their pages. The aim of the present article is to investigate the literary texts published by the black press in São Paulo between 1915 and 1931 by focusing the poetic production. The main assumption is that black intellectuals took political advantage of poetry to value the "black population". They aimed at not neglecting their aesthetic sense, as much as possible.

\section{PALAVRAS-CHAVE:}

negro;

raça;

intelectual;

imprensa;

literatura.

\section{KEYWORDS}

blackness;

race;

intellectual;

press;

literature.

I Universidade Federal de Sergipe, São Cristóvão, Sergipe, Brasil.

II Universidade de São Paulo, São Paulo, São Paulo, Brasil. 
Avante! homens de cor, à nossa ideia! Formemos nosso 'Centro', carinhoso, Dar Luz e instrução é ter o gozo De brilhante epopéia!...

Que Importa a nossa cor, se a nossa raça, Outrora maltratada, hoje ufanante, Nas páginas da história que ela traça, Levanta-se possante!...

Lembremos Patrocínio, o morto ilustre, E Gama, o grande herói, em outros tempos, Por isso, nós devemos com igual lustre Seguir os seus exemplos!...

poema acima, de autoria de Augusto Marques, foi publicado em 22 de junho de 1924 no Getulino, um jornal da imprensa negra. ${ }^{1}$ Intitulado "Avante!", o pequeno poema de apenas três estrofes catalisava algumas das características do discurso dos intelectuais afro-brasileiros no período. ${ }^{2}$ A primeira se referia à importância atribuída ao ideal de "união", visto como pré-requisito para a superação das adversidades enfrentadas pela "classe dos homens de cor". A segunda característica dizia respeito à valorização da educação, pois "dar luz e instrução é ter o gozo de brilhante epopeia". ${ }^{3}$ Educação, aqui, tinha um duplo sentido: de formação escolar, tendo em vista o negro se qualificar para obter melhores colocações no mercado de trabalho; e formação cultural e moral, no sentido de ele se "civilizar" e adquirir "bons costumes" e "boas maneiras", para conquistar respeitabilidade e aceitação por parte da sociedade. Já a terceira característica relacionava-se à demanda de uma nova narrativa da história nacional, que retratava o negro como tendo desempenhado um papel de fundamental importância na "construção do Brasil", o que revalorizava, para não dizer positivava, seu lugar na identidade nacional.

Outro modo de celebrar o valor do negro brasileiro era politizar a memória pública de personalidades desse segmento populacional,

\footnotetext{
${ }^{1}$ Cf. Getulino. Campinas, 22 jun. 1924, p. 2. Convencionou-se designar de imprensa negra o conjunto de periódicos (jornais e revistas) feito por afro-brasileiros, em diferentes temporalidades, que serviu de porta-voz de notícias e reflexões sobre suas vidas e o mundo no qual estavam inseridos, cf. BASTIDE, 1983, p. 129-56; FERRARA, 1986; MITCHELL, 1991-1992, p. 17-29; DOMINGUES, 2008, p. 19-58 e REIS, 2017.

2 Sobre os intelectuais afro-brasileiros desse período, v. BUTLER, 1988; ALBERTO, 2011 e MELLO, 2014.

${ }^{3}$ Cf. Getulino. Campinas, 22 jun. 1924, p. 2.
} 
alçando-as à categoria de ícones da "raça"(PINTO, 2013). Figuras como José do "Patrocínio, o morto ilustre", e Luiz "Gama, o grande herói em outros tempos" 4 , eram constantemente exaltadas, não só como modelos cujas vidas deveriam ser mimetizadas por sua grandeza histórica, mas porque esta grandeza atestava os atributos inquestionavelmente positivos do conjunto da população negra. Na verdade, os intelectuais afro-paulistas conferiam tanta importância aos "heróis da raça" que uma forma encontrada para homenageá-los foi adotar seus nomes para os órgãos de representação, a exemplo do Centro Humanitário José do Patrocínio, ${ }^{5}$ do Centro Cultural Henrique Dias, ambos da cidade de São Paulo; da Sociedade Beneficente Luiz Gama, de Campinas, dos jornais O Patrocínio, de Piracicaba, Getulino, de Campinas, ${ }^{6}$ e O Menelik, da capital paulista, por ser um nome "que não deveria, mas que era esquecido dos homens de cor, é esse o nome, o de Menelik II, grande rei da raça preta, falecido em 1913". ${ }^{7}$

É interessante saber que alguns dos principais "heróis da raça" como Luiz Gama, José do Patrocínio e Cruz e Souza - desenvolveram uma atuação literária. Publicaram em jornais e revistas, participaram de rodas de escritores, fizeram carreira editorial, enfim, destacaram-se no mundo das letras. ${ }^{8}$ Ao se certificar disso, os intelectuais negros aumentavam sua admiração pelos itinerários de personalidades que aliaram, em diferentes momentos, graus e latitudes, literatura (arte) e militância (política). Consideravam-se seguidores daqueles grandes ícones, buscando "com igual lustre" trilhar caminhos por eles pavimentados. ${ }^{9}$

Em artigo publicado no Getulino, em dezembro de 1924, José Luiz de Mesquita discorreu sobre "o negro na literatura nacional". Para se contrapor aos preconceitos correntes, que viam os negros como "burros e sem capacidade intelectual", Mesquita argumentava que isso era "asneira" e falta de conhecimento sobre a história do Brasil. A "literatura nacional não podia dispensar o concurso do negro", pois "teria um vácuo as letras brasileiras, se entre os seus mais ilustres próceres, um negro não figurasse". Para fundamentar o seu argumento, ele mencionava a contribuição literária de José Carlos do Patrocínio e João da Cruz e Souza. O primeiro foi o autor dos romances Motta Coqueiro, Os Retirantes, Pedro Espanhol, As meninas Godin, do Manifesto da Confederação Abolicionista, de algumas poesias, além de "centenas de discursos e conferências". Segundo Mesquita, as obras de "impecável correção" de José do Patrocínio

\footnotetext{
${ }^{4}$ Getulino. Campinas, 22 jun. 1924, p. 2.

${ }^{5}$ Dentre as homenagens ao jornalista, abolicionista e político carioca José do Patrocínio, citamos o poema de Leôncio Correia e um editorial homônimo, publicados na mesma edição do Getulino, Campinas, 9 out. 1924, p. 1.

${ }^{6}$ Getulino era uma das alcunhas pelas quais Luiz Gama era conhecido.

7 In: O Menelik. São Paulo, 17 out. 1915, p. 1.

${ }^{8}$ Sobre alguns literatos negros que se destacaram no eixo Rio de Janeiro e São Paulo durante o século XIX, v. PINTO, 2018.

${ }^{9}$ Cf. DOMINGUES, 2016, p. 389-416.
} 
mostravam com "facilidade" que ele manejava a "língua de Camões", o que fez com que fosse "eleito para a Academia [Brasileira] de Letras" e ganhasse "a admiração dos intelectuais, não só do Brasil, mas também da Europa". Outro que teria muito enriquecido a literatura nacional foi o "mavioso cantor das musas, filho de Santa Catarina, João da Cruz e Souza, o poeta negro, considerado o chefe da escola simbolista". De acordo com Mesquita, "hoje Cruz e Sousa é julgado pelos críticos com mais responsabilidade e crédito; com mais justiça, e lhe reconhecem o alto valor e merecimento incontestáveis" de suas obras "Missal, Broquéis, Faróis, Evocação e Últimos Sonetos". 10

O presente artigo tem a finalidade de abordar os textos literários publicados na imprensa negra de São Paulo entre os anos 1915 e 1931, atentos à "riqueza estética e comunicativa", mas preocupados especialmente com o "conjunto de significados condensados na sua dimensão social”" (SEVCENKO, 1999, p. 20). A literatura, em vez de uma instância autônoma em relação à realidade social, é tomada aqui como um testemunho histórico a ser explorado e analisado, a partir das interconexões entre autor, obra e contexto. ${ }^{11}$ Diversos periódicos se autodenominavam "órgãos literários"12 e, invariavelmente, traziam em suas páginas artigos, ensaios, notícias, ilustrações, propagandas, afora uma série de contos, crônicas, poemas e até romances. É de se admirar o tamanho do espaço que os textos literários recebiam nessas folhas.

"A poesia é a florescência radiosa e divina da espiritualidade". Assim começava Amadeu Amaral, um colaborador do jornal Getulino, ${ }^{13}$ a escrevinhar sobre essa forma literária tão apreciada pelos intelectuais negros em São Paulo. Talvez por permitir exprimir os sentimentos, anseios, ideais e sonhos mais recônditos da alma humana, a poesia era o principal eixo de ligação entre toda a imprensa negra paulista, de 1915 a 1931. Faziase presente em quase todas as edições da coleção desses periódicos. ${ }^{14}$

A poesia, "a mais fina e melindrosa expressão da vida intelectual",15 assumia nos jornais diversas facetas, variando nas formas, nos estilos e nos temas. Mesmo assim, é possível identificar alguns traços fundamentais e pontos de intersecção entre a produção poética de intelectuais negros. Para tanto, centraremos nosso olhar na produção de alguns poetas, que, em conjunto, reúnem as principais características da poesia difundida pelas folhas e associações negras. ${ }^{16}$ Aliás, estas associações, como bem realça

\footnotetext{
10 In: Getulino. Campinas, 20 dez. 1924, p. 8.

11 Cf. CHALHOUB; PEREIRA, 1998, p. 7.

12 Cf. A Liberdade. São Paulo, 14 jul. 1919, p. 1; A Rua. São Paulo, 24 fev. 1926, p.1; O Patrocínio. Piracicaba, 7 abr. 1928, p. 1; O Clarim. São Paulo, 6 jan. 1924, p. 1; para citar alguns exemplos.

13 Getulino. Campinas, 10 ago. 1924, p. 3.

${ }^{14}$ Havia algumas exceções: O Alfinete. São Paulo, 9 mar. 1919 e 28 set. 1921; O Bandeirante. São Paulo, set. 1918 e abr. 1919; O Xauter. São Paulo, 16 maio 1916.

15 Getulino. Campinas, 10 ago. 1924, p. 3.

16 As associações negras de São Paulo na época promoviam uma séria de atividades políticas, sociais, culturais e recreativas, entre as quais sessões "lítero-dramáticas", saraus e recitais de
} 
Cuti (Luiz Silva), começaram a oferecer nessa época uma recepção mais solidária aos intelectuais afro-brasileiros, "entusiasmando-os a escrever, tendo como endereço direto um leitor negro". Com isso, tais escritores "passaram a incluir na sua temática o protesto, desenvolvendo no texto uma consciência crítica” (CUTI, 2010, p. 29).

Fato é que a maioria desses intelectuais convergia na sua trajetória, articulando simultaneamente produção literária e ativa militância. Amiúde, a poesia assumia um tom pedagógico, engajado, combativo, o que denotava ser fundamental nos esforços em prol da valorização da "classe dos homens de cor", porém, não negligenciava - ou procurava não negligenciar - o seu sentido estético. Nas palavras de Amadeu Amaral, havia a necessidade de amar "com religioso fervor" aquela "arte, a misteriosa, a augusta, a eretora e benfazeja Poesia". ${ }^{17}$

$\mathrm{O}$ artigo é relevante por tratar de poetas pouco conhecidos e invisibilizados no sistema literário brasileiro, analisando suas trajetórias e estilos, e indexando informações sobre a imprensa negra como suporte e arquivo para textos literários que, se, por um lado, não encontravam muitas possibilidades de inserção e visibilidade em outros universos de circulação literária justamente por se tratar de autores negros, por outro, tomava o poema - e o suporte jornal - como plataforma de enunciação e visibilidade de experiências históricas, subjetividades e discursos amorosos, protestos negros, politização do cotidiano, entre outras questões.

\section{Deoclé}

"Um dos nomes de mais evidência na intelectualidade paulistana", que "enche de orgulho, no Brasil, a raça negra". Era assim como a gazeta Getulino ${ }^{18}$ definia Deocleciano Nascimento, um dos mais respeitados fomentadores da imprensa negra. Nascido em Minas Gerais e radicado em São Paulo, consta que "formou-se em comércio, pelo Lyceu Salesiano", desta cidade, "recebendo o grau de guarda-livros". ${ }^{19}$ Também atuou como contador, fazendo carreira na profissão.

Em 1915, Deocleciano Nascimento fundou O Menelik, jornal que marca o início de nossa baliza cronológica. Foi ainda redator do periódico Auriverde e, entre 1933 e 1936, d'A Voz da Raça, o veículo de comunicação oficial da Frente Negra Brasileira, além de representante do campineiro Getulino, na capital paulista. Em livro de memórias, José Correia Leite, que o conheceu bem em São Paulo, relata que Deocleciano Nascimento se

poesia. Sobre o associativismo negro, v. SILVA, 1998, p. 65-96; BUTLER, 1992, p. 179-206 e PIRES, 2006.

${ }^{17}$ In: Getulino. Campinas, 10 ago. 1924, p. 3.

18 Cf. Getulino. Campinas, 7 set. 1924, p. 1.

19 In: O Bandeirante. São Paulo, abr. 1919, p. 4. 
destacava. Era "uma espécie de Cruz e Souza no meio negro - um grande poeta. Ele deixou poesias esparsas. Não era um negro sem posição. Contador formado, ele exercia a profissão dele, muito importante na época" (LEITE, 1992, p. 45-6). Portanto, paralelamente às lides jornalísticas, Deocleciano se distinguiu como um literato bastante produtivo. Só no primeiro número d'O Menelik publicou dois poemas, dois contos e uma coluna assinada como "Deoclé", sem contar os textos dos editoriais não assinados, provavelmente de sua lavra. Podemos ver sua poesia ainda nos jornais Getulino, Auriverde, O Clarim d'Alvorada e O Kosmos.

Regozijo

À Exma. Sra. D. Maria José de Almeida, distinta oradora e presidente do Clube 13 de Maio de São Paulo

São dias felizes, repletos de venturas, Esses que vos leva de glórias rodeada, Porque sois vós a mais gentil e admirada Do quadro juvenil das lindas criaturas.

Nas festas certo é: das tantas formosuras, A voz da oradora, a ti é confiada; E ouve-se ela, terna, suave e denodada que de tu'alma vem guiadas de returas!

No meio da palavra que de tu'alma salta, as vozes - muito bem - do auditório, aparta a tua que é sonora, meiga e primorosa!

Sempre no final da tua oração Ouve-se profunda e longa ovação De palmas que dá glória a ti que és talentosa. ${ }^{20}$

Tal qual "Regozijo" - poema que estampava a primeira página da edição de lançamento d'O Menelik - a grande maioria dos escritos de Deocleciano Nascimento encontrava-se na forma de soneto. A escolha parecia deliberada. Um dos gêneros prediletos dos poetas brasileiros consagrados da época (a exemplo de Olavo Bilac), inclusive dos escritores negros, como Machado de Assis e Cruz e Sousa, o soneto é constituído por duas quadras e dois tercetos, ou seja, quatorze versos em geral decassílabos, que obedecem a uma rígida estrutura de rimas (abba/ abba/ cde/ cde e variações) e métrica. "Por essas características e pela dificuldade que interpõem ao poeta", afirma Massaud Moisés, "o soneto tem constituído uma espécie de pedra de toque para todos quantos se abalançam a escrever poesia" (MOISÉS, 1968, p. 81-2).

${ }^{20}$ In: O Menelik. São Paulo, 17 out. 1915, p. 1. 
Tudo indica que Deocleciano Nascimento estava ciente disso. Quando explicou o porquê do subtítulo de seu jornal, O Menelik, argumentou que "era literário para mostrar ao mundo a sabedoria que ocultamente vagueia no cérebro da classe [dos "homens de cor"]". Se este era o objetivo final, o soneto - como texto cuja estrutura exigia o domínio da língua, de rimas e métricas - era uma ótima maneira de expressar esta "sabedoria". Dessa perspectiva, dominar os preceitos estéticos e formais da literatura era "mostrar ao mundo" a sagacidade, o talento e a capacidade intelectual do negro brasileiro, e assim colocar em xeque as ideias racistas que preconizam o contrário. ${ }^{21}$ Aliás, o soneto foi a forma poética preferida dos literatos da imprensa negra.

Em "Regozijo", vemos a homenagem que o autor prestou a uma mulher, Maria José de Almeida, que em 1915 era "oradora e presidente" do Clube 13 de Maio, uma das sociedades cívicas, beneficentes, culturais e recreativas consolidadas da "comunidade negra" da capital paulista. ${ }^{22} \mathrm{~A}$ partir desse poema, verificamos como a preocupação com a métrica e a descrição de um "objeto" aproxima o autor da linguagem do parnasianismo, cuja poética se situa "na convergência de ideais antirromânticos, como a objetividade no trato dos temas e o culto da forma" (BOSI, 2015, p. 233).

Apesar de Deocleciano Nascimento demonstrar um inegável "culto da forma", não consideramos possível afirmar que esse poema, nem o conjunto de sua obra, apresentava a pura "arte pela arte, aspirando a desfazer-se de qualquer compromisso com os níveis da existência que não os do puro fazer mimético" (Idem, p. 235). Se o poeta escolheu homenagear uma figura feminina proeminente no associativismo negro, tal gesto revestia-se de um simbolismo político, o que talvez comprometia a "objetividade no trato do tema". Deparamo-nos, por assim dizer, com uma poesia dedicada às questões e aos desafios relacionados à população negra e à sua luta por autoestima, reconhecimento e protagonismo na sociedade brasileira. Conforme assevera Cuti, um dos meios empregados pelo autor "negro-brasileiro" para romper com o preconceito racial "existente na produção textual de autores brancos é fazer do próprio preconceito temas de suas obras, apontando-lhes as contradições e consequências. Ao realizar tal tarefa, demarca o ponto diferenciado de emanação do discurso, o "lugar" de onde fala" (CUTI, Op. cit., p. 25).

Entretanto, nem toda produção poética de Deocleciano Nascimento abordava os problemas, impasses e dilemas raciais. Há poemas em que o

${ }^{21}$ Cf. O Menelik. São Paulo, 17 out. 1915, p. 1. Sobre as ideias de caráter racista desse período, v. SCHWARCZ, Lilia M. O espetáculo das raças: cientistas, instituições e questão racial no Brasil. São Paulo: Companhia das letras, 1993.

${ }^{22}$ Deocleciano Nascimento escreveu outro texto em que homenageia as mulheres e o dedicou ao "quadro de damas" do G. R. José do Patrocínio, de Campinas. É o poema "Boas Festas", no qual ele evoca a beleza das flores: "De boas festas, eu sem ter receio/ vos darei flores, que eu colher do prado/ Em meros versos, que aceitá-los creio". In: Getulino. Campinas, 16 dez. 1923, p. 1. 
autor, por exemplo, conversava com "um passarinho" sobre uma mulher, perguntando: "não viste a turba encantada/ de faleninhas mimosas/ ao redor da minha amada/ risonha colhendo rosas?" 23 Ou seja, a preocupação central aqui era com o rigor formal (a rima, o ritmo, a métrica e o vocabulário rebuscado), demonstrando a "sabedoria" de Nascimento, que não se furtava de explorar em seus poemas o lirismo, o romantismo, o encômio, a elegia e diversas outras questões. Aparentemente, foi entre 1923 e 1924 que se concentrou a maior parte de sua produção literária relacionada à temática do negro como coletividade.

Pelo menos foi ao longo desses anos que Nascimento, quando publicava um poema, identificava-o como parte da "Musa Etiópica, em preparo". Este livro, que reuniria uma compilação de sua produção poética e traria o sujeito negro, seus problemas, suas questões e aspirações como o grande foco narrativo, nunca foi publicado. ${ }^{24}$ Entretanto, graças aos jornais afro-brasileiros do período, temos acesso a uma parte dele, como o poema "Evolução":

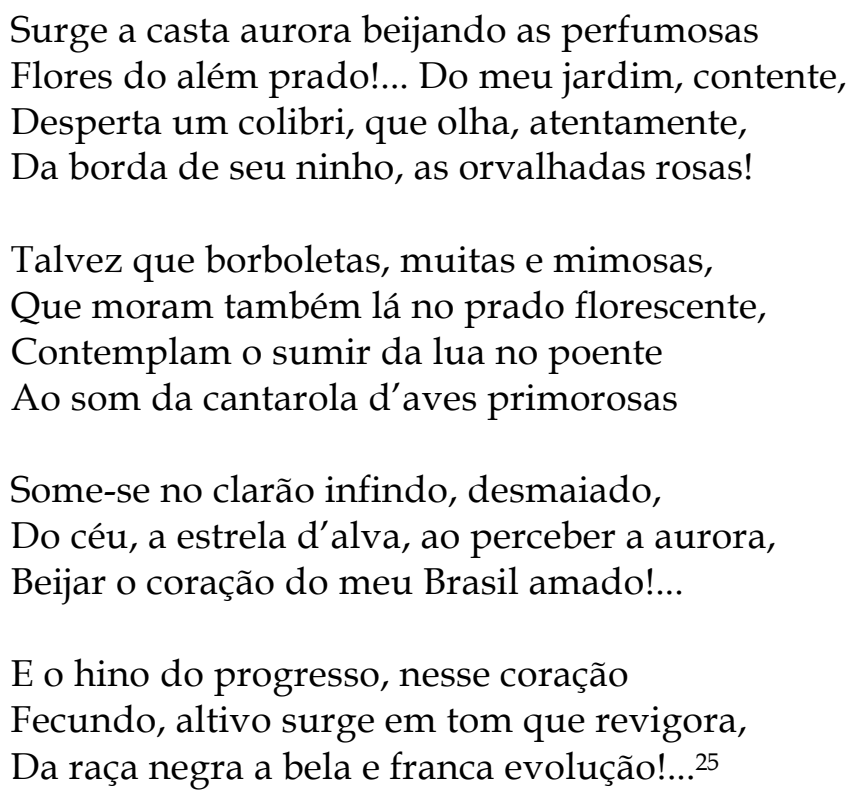

O poema saúda o nascer do sol, a "casta aurora", que surge das trevas e ilumina a natureza trazendo consigo a ideia de vida (de crisálida, vicejar e florescimento), representados pelos "colibris", "rosas" e "borboletas", entre outras metáforas. Da mesma forma o poema aclama o cenário da "bela e franca evolução" no "coração fecundo" e "altivo" da "raça negra". A retórica de "evolução" e "progresso", tanto material quanto moral, era uma constante na narrativa dos intelectuais negros, que tendiam a racializar a linguagem poética, em vista de sensibilizar os leitores para o problema da "população de cor" e atraí-los à marcha da

${ }^{23}$ In: O Auriverde. São Paulo, 29 abr. 1928, p. 3.

${ }^{24}$ Cf. AGUIAR, 1978, p. 134.

25 In: O Kosmos. São Paulo, 16 mar. 1924, p. 1. 
vitória. Deocleciano Nascimento trouxe à tona, em 1924, versos bastante didáticos, que também faziam parte da obra "Musa Etiópica". Nessas composições, ele conversava com um "poeta negro" - talvez ele mesmo e apontava sobre o quê este deveria escrever. Não deveria produzir qualquer verso, mas "versos imortais", já que o "poeta negro" precisava ser "altivo em plena linha reta".

Na margem dum formoso ribeirão,

Eu vi-te pensativo!

Que pensavas, genuíno coração,

Dos poemas cativo?...

Meditavas algum fecundo tema,

À meiga poesia,

Daquele deslizar de água fria,

Um lindo teorema!

Eu vi que tu: poeta com amor,

Olhava-te nascente,

Enquanto, então, da líquida corrente,

Ouvia-se o rumor.

Oxalá que um anjinho meigo e louro,

Embalando o teu sonho,

Condene-te a traçar com pena d'ouro

Um poema risonho!

Aí tu deves, genial poeta,

Uns versos imortais,

traçar, altivo em plena linha reta,

À raça de teus pais. ${ }^{26}$

Deocleciano Nascimento roga que o "poeta negro" produza "versos imortais" em memória à "raça" de seus ancestrais, mas, em última instância, esta súplica também servia para ele mesmo. Se a prática de racializar a poesia era algo comum entre os literatos que publicavam na imprensa negra, Nascimento não se furtou de explorar outros assuntos, como um "amor de carnaval". No poema "lindinha", ele contava como durante o "esplendor de um baile à fantasia/ vi-te, mimosa, muito bem vestida". Era uma moça que também teria se deslumbrado pelo bardo, mas "esse amor, sem amor sentimental/ foi um sonho sonhado por nós dois/ num delírio sem par, num carnaval" ${ }^{27}$ Este esforço estético de Nascimento se fez presente em outro poema, "Do meu canto". Julgando-se ainda pouco capaz na "arte", o autor se rendia ao desejo, quase uma necessidade, de compor seu "canto". Deocleciano Nascimento - o "mavioso cantor da

\footnotetext{
26 In: Getulino. Campinas, 13 jul. 1924, p. 1.
}

27 In: Getulino. Campinas, 2 mar. 1924, p. 4. 
Musa Etiópica", ${ }^{28}$ como os editores do Getulino o qualificaram - versejava ao leitor a sua lida (e sua lira).

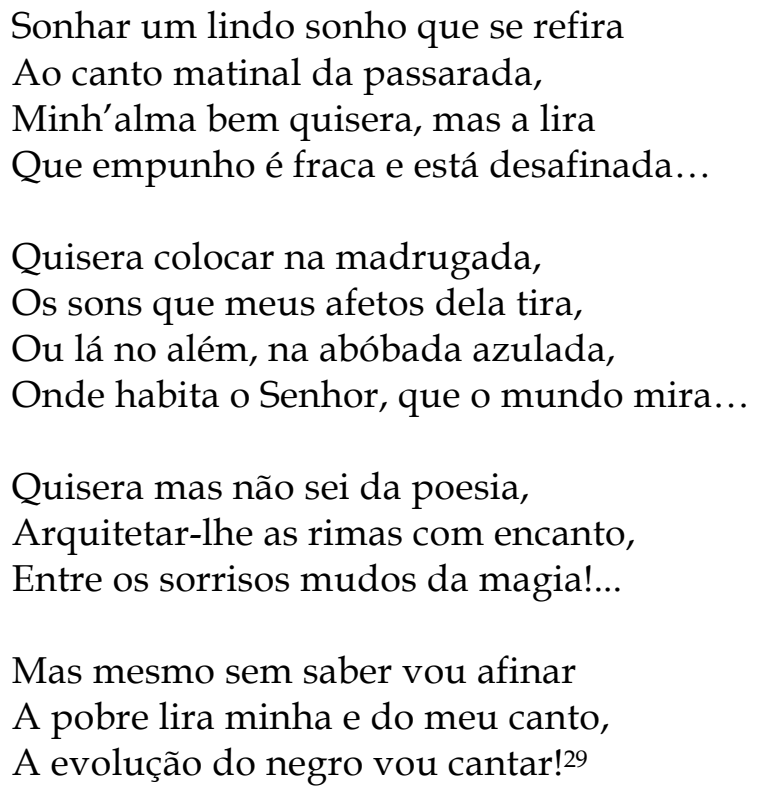

Deocleciano Nascimento notabilizou-se como um poeta cioso, que investia no aprimoramento estético. Não é à toa que ele era visto como um "artista da palavra e dedicado compilador de mimosas joias literárias". 30 Apesar disso, não perdia no horizonte a possibilidade de se utilizar da poesia como instrumento de (re)construção identitária e conscientização da população negra, que deveria desenvolver seu senso de solidariedade, dignidade e orgulho racial, além de "evoluir" e "progredir" cada vez mais na vida, rumo à conquista da sua inserção à comunidade nacional, com direito a reconhecimento e representatividade.

\section{Laly, Leite e Jim de Araguary}

Assim como Deocleciano Nascimento, outros três intelectuais negros - Laly, Leite e Jim de Araguary - uniram atividade jornalística e literária em torno de um ideal. Todos os três eram pseudônimos e suas respectivas produções poéticas serão discutidas doravante.

Laly não é desconhecido da bibliografia como Deocleciano Nascimento. Roger Bastide (Op. cit.), David Brookshaw (1983), Zilá Bernd (1988), Benedita Damasceno (1988), Petrônio Domingues (2010), Cuti (Op. cit.), Heloísa Toller Gomes (2011), Oswaldo de Camargo (2016), Mário Augusto da Silva (2017), entre outros, debruçaram-se sobre diversos aspectos da vida e obra do intelectual que geralmente é considerado um

\footnotetext{
28 In: Getulino. Campinas, 16 out. 1923, p. 1.

29 In: Getulino. Campinas, 20 jan. 1924, p. 2.

30 In: O Menelik. São Paulo, 1 jan. 1916, p. 2.
} 
baluarte da literatura negra das primeiras décadas do século XX. Referimonos ao jornalista e escritor Lino Pinto Guedes.

Nascido em 24 de junho de 1897 na cidade paulista de Socorro, Lino Guedes era filho de dois ex-escravizados: José Pinto Guedes e Benedita Eugênia Guedes. Sua criação e a de sua irmã Gracinda ficou a cargo de dona Benedita, pois seu pai morreu quando Laly ainda era um bebê. Com a ajuda paternalista de Olímpio Gonçalvez dos Reis, ex-senhor dos seus pais, frequentou o grupo escolar da sua cidade natal. Aos 15 anos de idade mudou-se para Campinas, tendo sido contratado como revisor auxiliar do Diário do Povo. Ao mesmo tempo, passou a frequentar diversas associações, como a Sociedade União Cívica dos Homens de Cor. Em 1915, editou A União, o jornal dessa agremiação. Assim, aos 17 anos de idade iniciava sua trajetória na imprensa negra paulista.

Em 1923, na companhia de Gervásio de Moraes, outro jornalista negro, fundou e tornou-se o redator-chefe do Getulino, o periódico de propriedade dos irmãos Martinho e José de Andrade. ${ }^{31}$ Foi atuando neste jornal que Guedes alcançou prestígio no "meio negro". ${ }^{32}$ Com o tempo, Campinas tornou-se uma cidade pequena diante de suas experiências e horizontes de expectativas. Migrou para a capital em 1926, quando escreveu seu primeiro artigo n'O Clarim d'Alvorada, ${ }^{33}$ uma folha na qual, dois meses depois, inaugurou a coluna "Klaxonadas",34 sob o pseudônimo de Laly. Em 1928, apareceu o Progresso, periódico no qual era o redatorchefe. Foi nessa fase que consolidou seu prestígio como importante figura do associativismo negro. Seus textos, tanto no Progresso quanto nas colaborações em outros jornais, eram coerentes com sua retórica na época do Getulino, preconizando a "evolução moral", o "amor à pátria" e o "progresso da raça". Também trabalhou nos órgãos da grande imprensa, como o Jornal do Comércio e o Diário de São Paulo, onde permaneceu até a sua morte em 1951.35

Afora as lides jornalísticas, Lino Guedes se destacou como escritor. Cedo, aliás, sua verve literária foi reconhecida. Já em 1925, O Clarim d'Alvorada elogiava seus "dotes literários" que, por ser "jovem ainda", dizia o jornal, "tem diante de si um largo futuro, que será por certo aproveitado para engrandecer a nossa raça". ${ }^{36}$ Dois anos mais tarde, os redatores d'O Clarim assinalavam que o "novo poeta que surge está destinado a conquistar, futuramente, muitas glórias", pois sua obra compõe "um punhado de versos que traduz seu grande sentimento, de uma literatura negra" ${ }^{37}$ Os prognósticos d'O Clarim se confirmaram. Ao

\footnotetext{
31 Sobre a trajetória do jornal Getulino, v. MACIEL, 1997, p. 96-102 e MIRANDA, 2005.

32 In: O Clarim d'Alvorada. São Paulo, 25 jan. 1925, p. 3.

33 In: O Clarim d'Alvorada. São Paulo, 24 jan. 1926, p. 2.

34 In: O Clarim d'Alvorada. São Paulo, 21 mar. 1926, p. 1.

35 Cf. DOMINGUES, Petrônio. Op. cit., p. 133-45.

36 In: O Clarim d'Alvorada. São Paulo, 27 dez. 1925, p. 2.

37 In: O Clarim d'Alvorada. São Paulo, 18 jun. 1927, p. 2.
} 
longo da vida, Guedes publicou diversos livros, principalmente de poesia. ${ }^{38} \mathrm{E}$ é considerado - por diversos estudiosos (como David Brookshaw, Cuti e Zilá Berd) - um dos autores emblemáticos da chamada "literatura negra" no Brasil, por trazer em seus textos o "eu-enunciador". Sua obra, assim, seria inovadora ao demarcar a presença do negro - para além de mero objeto, como era corrente na literatura da época - como sujeito de ação poética, literária. ${ }^{39}$

Curiosamente, nem no Getulino ou no Progresso, jornais que estiveram sob a direção de Guedes, estamparam alguma composição do "aplaudido poeta". Consultando outros periódicos desse período, encontramos apenas dois poemas de sua lavra. ${ }^{40}$ Pode ser que ele não queria "advogar em causa própria", preferindo abrir espaço para os novos poetas. Fato é que Guedes aproveitou a tribuna da imprensa negra para expressar suas ideias, fundamentalmente, sob a forma de artigo. De todo modo, vale a pena tecer alguns comentários acerca de um de seus poemas localizados:

\author{
Um diabinho é Aracy \\ Parece até um Sacy \\ A travessa da negrinha \\ Em certa roda de samba \\ Fica a gente meio bamba \\ Com a graça da tiazinha \\ Indiscretos arregaços \\ Da saia mostram os passos \\ A poesia que tem \\ O samba. Ela requebrando \\ A todos vai convidando \\ Para dançarmos também. \\ E a Aracy, um certo dia \\ Aparece, quem diria, \\ Feita estrela teatral! \\ E ao refulgir da ribalta
}

38 Canto do Cysne Preto (1927), Black (1927), Ressurreição Negra (1928), Negro Preto Cor da
Noite (1932), Urucungo (1936) e Suncristo (1951) são alguns dos livros de autoria de Lino Guedes.
39 Cf. BERND, Op. cit. Eis como Cuti se refere a Lino Guedes: “Cronista da vida urbana dos negros
no pós-Abolição, com sua forma poética de linguagem simples, Lino erige a população negra
como destinatária de seu discurso e motivo poético e, no indeterminado, vislumbra a
discriminação racial. [...] É possível vislumbrar o nascimento de um horizonte onde inicia-se uma
nova jornada de expectativa e possibilidade: o olhar do leitor negro". CUTI, Op. cit., p. 83. V.
ainda BROOKSHAW, Op. cit.
40 Cf. “Carvão Nacional”, In: O Patrocínio. Piracicaba, 7 set. 1928, p. 1 e “A esperança”. In: O Clarim
d'Alvorada. São Paulo, 26 jul. 1925 , p. 3 . É bastante provável que mais poemas de Lino Guedes
tivessem sido publicados n'O Clarim d'Alvorada. Embora a coleção deste periódico esteja
incompleta e, por isso, não tenha sido possível consultá-la na íntegra, constatamos que, na edição
de 1925, ele elogiava Guedes, "de quem já publicamos uns excelentes versos”. O Clarim
d'Alvorada, São Paulo, 27 dez. 1925, p. 2 . 
Toda a negrada se exalta

Com o carvão nacional ${ }^{41}$

O poema supracitado, "Carvão Nacional", foi publicado n'O Patrocínio, uma gazeta da cidade de Piracicaba. Seu título era uma alusão a um quadro da peça "Preto e Branco", encenada pela Companhia Negra de Revistas, que posteriormente também levou para os palcos um espetáculo com título homônimo. Nascida no Rio de Janeiro em 1926, sob o comando de De Chocolat e de seu sócio Jaime Silva, a Companhia Negra de Revistas era um grupo teatral que reunia músicos, dançarinos e artistas negros de renome. Sua estreia se deu com a peça "Tudo Preto", que foi seguida por "Preto e Branco" e "Carvão Nacional". Durante seu curto período de existência, entre 1926 e 1927, a Companhia Negra de Revistas excursionou por várias cidades do Brasil, levando para os palcos músicas, danças, temas, símbolos e outras manifestações culturais afro-diaspóricas e, na maior parte das vezes, causando frisson e alcançando sucesso de público. ${ }^{42}$ Quando esteve em São Paulo, a troupe marcou época no meio cultural negro. Lino Guedes, muito provavelmente, foi assisti-la e, assim como os seus "irmãos de cor", ficou encantado com a qualidade da produção da Companhia, a ponto de resolver homenageá-la compondo um poema.

A protagonista do poema é Aracy, uma referência à talentosa e exuberante cantora e atriz afro-brasileira Aracy Cortes, considerada na época a "rainha do teatro de revista". ${ }^{43}$ Seu sucesso no meio artístico, aliás, inspirou o próprio surgimento da Companhia. Na pena de Guedes, Aracy aparecia como símbolo da mulher negra, sob a metáfora do "carvão nacional". Graciosa, seu corpo seria uma verdadeira obra da natureza, por isso a "travessa da negrinha" deixava a "gente meio bamba". A mulher negra era retratada de um ponto de vista que singularizava e privilegiava sua beleza fisionômica. Quando se torna "estrela teatral", Aracy, que já se destacava em "certa roda de samba", teria passado a ser admirada por "toda a negrada". A admiração pela mulher negra, assim, alcançaria outro patamar ante a fama e o sucesso - o "refulgir da ribalta". Nesse poema, é possível notar como os versos harmonizam forma e conteúdo na abordagem da questão racial interseccionada com a clivagem de gênero. A mensagem de Guedes era apoteótica: viva o "carvão nacional", o que significava dizer que o "fecho de ouro", comum nos sonetos, trazia como mote a valorização da mulher negra. Se Laly é tido por David Brookshaw como o "primeiro poeta negro do Brasil a experimentar e expressar conscientemente a alma de seu povo" (BROOKSHAW, Op. cit., p. 177), ele não foi o único de sua geração.

\footnotetext{
${ }^{41}$ In: O Patrocínio. Piracicaba, 7 set. 1928, p. 1.

${ }^{42}$ Cf. BARROS, 2005 e GOMES, 2004, especialmente o capítulo "Raça e nação na trajetória da Companhia Negra de Revistas".

${ }^{43}$ In: RUIZ, 1984.
} 
José Correia Leite e Jayme de Aguiar (cujo pseudônimo Jim de Araguary é um anagrama) foram parceiros de longa data na militância negra. Os dois tiveram infâncias distintas, porém emblemáticas das experiências de vida de parcela da "população de cor" em São Paulo. Ambos cresceram no bairro do Bixiga. Leite, filho de empregada doméstica, enfrentou sérias dificuldades financeiras quando criança, o que lhe trouxe barreiras ao acesso à escola, por exemplo. Não cursou sequer o "primário". ${ }^{44}$ Aguiar, por sua vez, era de uma família "protegida por antigos senhores - os Paula Souza", situação que lhe permitiu estudar no "Coração de Jesus, um colégio em que não entrava qualquer um naquele momento" 45 e mais tarde se formar como contador, embora tenha feito carreira como datiloscopista. Ambos se conheceram ainda na infância, fase em que contraíram laços de amizade, inclusive brincando juntos pelas imediações do Bixiga. Anos depois se reencontraram, já adultos, em um baile promovido por um dos diversos clubes negros existentes em São Paulo na época. A partir daí os caminhos dos dois se tornaram cada vez mais cruzados. Como Leite descreve:

Um dia reencontrei o Jayme de Aguiar. Já não era mais aquele moleque. Dei com ele num baile. Ele fez festa comigo. Era acostumado a frequentar bailes de sociedades. Só que tinha uma coisa que me incomodava. O Jayme de Aguiar, em todo nosso encontro, punha a mão no bolso e tirava um soneto e lia para eu ouvir. E, o que eu entendia de soneto? Outras vezes tirava uma crônica que ele não tinha onde publicar e lia também. Ele conhecia negros redatores de jornais...

Um dia ele me disse:

- Zé, você não vai se ofender, mas eu posso te dar umas aulas de português para ajudar a melhorar?

Eu respondi prontamente:

- Me ofender? Não. Você me faz um grande favor. É só marcar. (LEITE, 1992, p. 26-9)

Não tardou e Leite logrou o domínio do letramento, o que lhe permitiu burilar os primeiros sonetos. A esta altura, uniu-se forças com Aguiar e fundaram, em 1924, O Clarim d'Alvorada, um jornal "noticioso" e "literário". ${ }^{46}$ Ambos publicaram poemas em outros órgãos da imprensa negra, como $O$ Patrocínio, ${ }^{47}$ Auriverde ${ }^{48}$ e Getulino ${ }^{49}$ Todavia, ao contrário de Lino Guedes, o principal canal de divulgação da produção intelectual

\footnotetext{
${ }^{44}$ Cf. FERREIRA, 2005.

${ }^{45}$ In: MOREIRA, s/d.

${ }^{46}$ Cf. FRANCISCO, 2013.

47 O Patrocínio. Piracicaba, 7 abr. 1927, p. 2.

48 Auriverde. São Paulo, 15 abr. 1928, p. 1.

${ }^{49}$ Getulino. Campinas, 23 nov. 1924, p. 2.
} 
deles foi o periódico que editavam. No primeiro número, quando ainda se chamava apenas O Clarim, temos noção de como Leite e Jim da Araguary eram vistos por eles próprios e pelos seus "irmãos de cor". Embora ambos participassem do associativismo negro, o primeiro respirava ativismo político e popular, escrevendo mais artigos assertivos, organizando eventos e ações coletivas, além de se engajar na formação de entidades em defesa dos "homens de cor", ao passo que o segundo era mais literato, autoidentificava-se como "poeta" e não dispensava laivos eruditos. ${ }^{50} \mathrm{Nas}$ folhas O Patrocínio e Auriverde, por exemplo, Leite publicou apenas artigos, enquanto Aguiar, poemas. ${ }^{51}$ Algo semelhante ocorreu na edição inaugural d' O Clarim, que estampou, lado a lado, um artigo ("a união faz a força") do primeiro e um poema ("as flores") do segundo. 52

A produção poética de Aguiar se distinguiu pelo lirismo. A composição de versos, em redondilhas maiores e rimas alternadas e interpoladas, demonstravam sua experiência do fazer poético. Além das redondilhas, dominava com rigor a técnica do soneto, conforme é possível depreender do poema "Lembrança", que aborda as vicissitudes do amor:

\author{
Sonhar com quem amamos que ventura \\ quando a certeza aponta a realidade, \\ quando esse afeto há muito que perdura \\ sem dissabores, sem falsidade!... \\ É assim o reviver da mocidade, \\ da linda primavera sempre pura; \\ - para o ancião felizardo uma saudade \\ ao job da sorte apenas desventura \\ Sonhadores que andais por essas vias, \\ pela estrada da vida, nestes dias, \\ cantarolando para não chorar, \\ Eu quisera sonhar e ter ao lado \\ aquela idolatrada do passado, \\ que já não vive; mas que soube amar!...53
}

Enquanto Jayme de Aguiar trazia a lume seus poemas em vários jornais e no seu próprio, desde o primeiro número, José Correia Leite demorou um pouco mais para colocar a mão na pena e produzir os seus versos. Em 1925, mais de um ano depois do lançamento d'O Clarim, entrou em cena o bardo Leite, com a publicação do poema "Vida que passa tão triste!". ${ }^{54}$ Sua linguagem era simples, baseada num esquema de rima popular, logo, destituída de qualquer pendor erudito. Mas com o tempo

\footnotetext{
${ }^{50}$ Cf. MOREIRA, Op. cit.

${ }^{51}$ Cf. O Patrocínio. Piracicaba, 20 out. 1929, p. 7.

52 Cf. O Clarim. São Paulo, 6 jan. 1924, p. 3

${ }^{53}$ In: O Clarim d'Alvorada. São Paulo, 27 dez. 1925, p. 3.

54 In: O Clarim d'Alvorada. São Paulo, 26 jul. 1925, p. 2.
} 
ele foi ampliando o cabedal poético, diversificando os recursos estilísticos, aperfeiçoando-se no domínio da técnica, até se utilizar do recorrente soneto para dar vazão à sua sensibilidade, aos seus sonhos e ideais. No poema "Aos Palmares", publicado na edição especial d'O Clarim em comemoração ao 13 de Maio, vemos Leite valer-se de sua faceta literária:

\author{
Aos Palmares \\ Das solidões das selvas africanas, \\ os legendários homens medievais \\ que nos legaram forças soberanas, \\ à conquistar as glórias atuais; \\ Assombradores das raças humanas, \\ pelos seus feitos foram imortais: \\ - andaram sempre nas garras tiranas, \\ do cativeiro que não volta mais!... \\ Hoje, cantamos, nesta nossa lira, \\ toda a grandeza dos antepassados \\ que a humanidade toda se admira. \\ Ao reviver, nas páginas da história \\ encontraremos os feitos conquistados, \\ que o grande povo só colheu vitória! 55
}

Evocando a memória do quilombo dos palmares, o soneto confere destaque à "grandeza dos antepassados" africanos que a humanidade toda admira, ou deveria admirar. Apropriando-se talvez dos referenciais, signos e narrativas em circulação na rede do Atlântico Negro naquele instante, Leite abordava questões relacionadas à história, cultura e identidade afro-diaspórica. ${ }^{56}$ É possível notar como ele atribui centralidade a uma África mística e idealizada das autênticas origens negras. ${ }^{57} \mathrm{~A}$ ancestralidade africana teria legado aos afro-brasileiros não só "legendários homens", que "pelos seus feitos foram imortais", como ainda as "forças soberanas" necessárias para "conquistar as glórias atuais". Se o discurso dos intelectuais negros na época era o da pertença à "comunidade nacional" - em vista de tentar transformar o negro na raiz de uma "brasilidade" -, 58 isso não significa renegar a herança ancestral. Ao mesmo tempo que demarcava território como poeta e (re)inscrevia uma identidade afro-brasileira, Correia Leite agenciava a memória do cativeiro. No que tange a este aspecto, o soneto positivava o papel da população negra na

\footnotetext{
55 In: O Clarim d'Alvorada. São Paulo, 13 maio 1926, p. 2.

56 Cf. SEIGEL, 2009 e BUTLER, 2011, p. 137-56.

57 Sobre as imagens e representações sobre a África na imprensa negra, v. SANTOS, 2012 e REIS, 2016.

58 Cf. MELLO, 2014 e ANDREWS, 1998.
} 
formação do Brasil. Bastaria um olhar atento às "páginas da história". Mesmo vivendo sob as "garras tiranas" da escravidão, esse segmento populacional teria conquistado "feitos" na construção da nação, o que permitiu que ele e o brasileiro em geral só colhessem "vitórias".

Percebe-se como o vate Correia Leite foi acumulando experiência no mundo das letras. Em um pequeno soneto, de apenas 14 versos, vemo-lo levantar a bandeira do protagonismo negro na formação da nação, assim como celebrar o patrimônio histórico africano, com suas origens, legados, conexões e memórias ressignificadas do outro lado do Atlântico. É essa força inerente à literatura que provavelmente estimulou os intelectuais negros a produzirem poemas. Nem sempre, como no caso do Jayme de Aguiar, essas produções veiculavam mensagem políticas, de afirmação racial ou identidade negra, mas, conseguir demarcar posição mediante o domínio dos recursos formais da linguagem poética (como métrica, rima e ritmo), numa sociedade que via o negro como inferior e incapaz intelectualmente, assumia, per si, contornos e significados políticos.

Nas páginas d'O Clarim há um único poema composto a quatro mãos pela dupla Leite e Jim da Araguary. O texto literário - oriundo de uma parceria tão profícua e engenhosa, que fez desse jornal um dos mais influentes e longevos da imprensa negra brasileira - não deixou de pautar um tema relativo à população negra. O poema "A Vitória", de janeiro de 1926, comemora os dois anos daquela parceria e consiste em um verdadeiro chamado à mobilização e luta no campo dos direitos, do reconhecimento e da identidade, o que sintetiza, em um soneto, muito do que seria o grande objetivo daqueles intelectuais negros:
A Vitória
Pela harmonia de uma raça inteira
Nós batalhamos tão valentemente; batalhando, pedimos que Deus queira, que esta vitória surja brevemente.
Marchando firmes, na fatal jornada de ver a classe muito bem unida, hão de ouvir sempre o toque d'Alvorada deste panfleto tão cheio de vida,
Das lutas que ficaram no passado, nesta jornada longa, não vencida, só simpatias temos conquistado
Só contamos com essa mocidade de homens sensatos, nesta grande lida para elevar a nossa identidade

Jim de Araguary \& Leite ${ }^{59}$

59 In: O Clarim d'Alvorada. São Paulo, 24 jan. 1926, p. 1. 
A imprensa negra desempenhou um papel de suma importância como polo de comunicação e aglutinação de intelectuais afro-brasileiros entre 1915 e 1931. Entre os editores, jornalistas e articulistas daqueles periódicos, circulavam algumas ideias comuns sobre um mesmo ideal: a "redenção da raça". Para eles, havia a necessidade de a "população de cor" unir-se e se associar a fim de se fortalecer no plano da identidade, cultura e política e promover ações coletivas contrárias ao "preconceito de cor"; investir na educação, tanto no sentido de instrução escolar como formação "moral" e "cultural"; defender um projeto de inserção social e reconhecimento por parte da comunidade nacional, afinal, o negro, como principal responsável pela edificação e desenvolvimento do Brasil, seria o segmento populacional que mais genuinamente personificava os interesses da pátria.

A imprensa negra serviu de canal divulgador de ideias não só no campo jornalístico ("noticioso"), mas também literário. Pudera. Era a literatura algo que perpassava toda a produção escrita dos intelectuais afro-brasileiros. Isso não significa que sua prática fosse fácil. Conforme postulava O Kosmos em 1923, a literatura, esta "arte da palavra", era "de todas as artes a mais bela, a mais expressiva, a mais difícil". ${ }^{60}$ Seja como for, um "punhado de versos" ganhou as páginas dos jornais da imprensa negra, que procuravam traduzir o "grande sentimento". Ultimamente, os editoriais, artigos e reportagens dessa imprensa estão cada vez mais comparecendo à agenda dos pesquisadores, porém o mesmo não se pode dizer de sua literatura, que ainda carece de estudos sistemáticos. ${ }^{61}$ Há de se estranhar que isso ocorra, tendo em vista o amplo espaço que aqueles periódicos reservavam aos textos literários, os quais, por sua vez, permitiam captar certas ideias, expectativas, retóricas e mensagens que, em um texto argumentativo, nem sempre era possível.

No que diz respeito à obra poética, verificamos que os intelectuais negros se valeram de sua produção à luz da arte e política. Os poemas veiculados pela imprensa negra, ora tinham uma preocupação estética, ora assumiam um caráter militante, mas antes procuravam, na medida do possível, conjugar as duas dimensões da "arte da palavra".

A produção poética era divergente na forma, no estilo e no teor, assumindo significados heterogêneos e polissêmicos de acordo com a autoria e o contexto. Servia para o negro letrado vocalizar suas subjetividades, esperanças, aspirações, veleidades e utopias, assim como atestar as suas potencialidades intelectuais, quando não a sua erudição, no trato com a linguagem literária. Servia como ferramenta de (re)afirmação identitária e simbólica, quando ressoava um discurso de orgulho racial e

${ }^{60}$ In: O Kosmos. São Paulo, 21 fev. 1923, p. 1.

${ }^{61}$ Uma exceção é a pesquisa de REIS, Op. cit. 
valorização dos homens e mulheres de "cor". Desempenhava uma função pedagógica ou mesmo doutrinária, já que procurava sensibilizar a população negra para seus problemas, dilemas, impasses e desafios no campo dos direitos, do reconhecimento e representatividade. Cumpria, ainda, um papel misto de protesto e combate, na medida em que os versos, embora traçados pela pena do vate, quando colocados em circulação assumiam o sentido de arma na luta antirracista. ${ }^{62}$

De uma perspectiva stricto sensu, aquela produção poética fazia parte do que Zilá Bernd define como "poesia negra", que se caracteriza pela "reversão de valores", com o estabelecimento de uma "nova ordem simbólica" oposta aos sentidos hegemônicos, e, sobretudo, pela emergência de um eu enunciador. Constituindo-se como espaço privilegiado da manifestação da subjetividade, "o poema negro reflete o trânsito da alienação à conscientização. Assim, a proposta do eu lírico não se limita à reivindicação de um mero reconhecimento, mas amplifica-se, correspondendo a um ato de reapropriação de um espaço existencial que lhe seja próprio" (BERND, 1988, p. 77) ${ }^{63}$

Já de um ângulo lato sensu, a produção poética da imprensa negra se inscrevia na categoria "literatura afro-brasileira", uma literatura que, segundo Eduardo de Assis Duarte, distingue-se por uma voz autoral negra, explícita ou não na narrativa; temas afro-brasileiros; construções "linguísticas marcadas por uma afro-brasilidade de tom, ritmo, sintaxe ou sentido; um projeto de transitividade discursiva, explícito ou não, com vistas ao universo recepcional; mas, sobretudo, um ponto de vista ou lugar de enunciação política e culturalmente identificado à afrodescendência". Seria, portanto, a interação desses cinco componentes - autoria, temática, ponto de vista, linguagem e público - que conceituaria a "literatura afrobrasileira". No entanto, Assis Duarte adverte para o fato de que se trata de um conceito em construção. Literatura afro-brasileira: processo, devir. Ao mesmo tempo "dentro e fora" da literatura brasileira. Dentro porque se vale da mesma língua e, praticamente, das mesmas formas e processos de expressão. Mas que está fora porque, entre outros motivos, não se coaduna com o ideal de instituir o advento do espírito nacional. Uma produção que implica mudanças de sentido à história literária canônica, na medida em que engendra uma escritura que seja não apenas a expressão dos afrobrasileiros como agente de cultura e de arte, mas que assinale o "etnocentrismo que os exclui do mundo das letras e da própria civilização. Daí seu caráter muitas vezes marginal, porque fundada na diferença que

\footnotetext{
62 A esse respeito, v. o poema "Preconceito", que Deocleciano Nascimento publicou na revista $O$ Malho e o dedicou à Frente Negra Brasileira. Rio de Janeiro, 6 fev. 1932, p. 10.

${ }^{63}$ Sobre a "poesia negra", v. ainda AUGEL, 1992, p. 261-78 e FIGUEIREDO; FONSECA, 2002.
} 
questiona e abala a trajetória progressiva e linear de nossa história literária" (DUARTE, 2015, p. 28-9; 41-2). ${ }^{64}$

Independentemente de se esquadrinhar os poemas da imprensa negra à luz da categoria "poesia negra" ou "literatura afro-brasileira", importa saber que eles adquiriram dimensões multifacetadas, indo para além de sua conotação artística. Levando em conta que a reconfiguração da realidade social fazia parte do horizonte de expectativas da autoria - de Deocleciano Nascimento, Lino Guedes, José Correia Leite e Jayme de Aguiar -, eles constituíram uma arena pública de expressão de ideias, de produção de contranarrativas, de debates e embates no seio da população negra e da sociedade de modo geral, de denúncias e propostas que acenavam por direitos, cidadania e igualdade. $\mathrm{O}$ entrelaçar de versos e experiência negra, eis a fórmula de poemas que carreavam, em via de mão dupla, arte a vida.

Para finalizar, convém salientar que o recorte temporal, de autores e textos proposto no artigo permitiu adentrar tanto a leitura contextual e histórica quanto estética e formal. $\mathrm{O}$ artigo tratou de questões e autorias pouco analisadas pela crítica literária, ressaltando seu caráter de ineditismo.

\section{Referências bibliográficas}

AGUIAR, Jaime de. "Depoimento", Revista do Instituto de Estudos Brasileiros, São Paulo, n. 20, 1978, p. 134.

ALBERTO, Paulina L. Terms of inclusion: black intellectuals in twentiethcentury Brazil. Chapel Hill, N.C.: The University of North Carolina Press, 2011.

ANDREWS, George Reid. Negros e brancos em São Paulo (1888-1988). Bauru: Edusc, 1998.

AUGEL, Moema Parente. "Poesia negra é força de quilombo". Estudos Lingüísticos e Literários. Salvador, n. 13, 1992, p. 261-78.

BARROS, Orlando de. Corações de Chocolat: a história da Companhia Negra de Revistas (1926-27). Rio de Janeiro: Livre expressão, 2005.

BASTIDE, Roger. "A imprensa negra do estado de São Paulo". Estudos afrobrasileiros. São Paulo: Perspectiva, 1983 (2ª ed.), p. 129-56.

BERND, Zilá. Introdução à literatura negra. São Paulo: Brasiliense, 1988.

BOSI, Alfredo. História concisa da literatura brasileira. São Paulo: Cultrix, 2015 (50a. ed.), p. 233.

BROOKSHAW, David. Raça \& cor na literatura brasileira. Porto Alegre: Mercado aberto, 1983.

${ }^{64}$ No que concerne à "literatura negra", conferir PROENÇA FILHO, 1988, p. 77-109 e FONSECA, 2014, v. 4, p. 245-77. 
BUTLER, Kim D. "Up from slavery": afro-brazilian activism in São Paulo, 1888-1938. The Americas, v. 49, n. 2, 1992, p. 179-206.

BUTLER, Kim D. Freedoms given, freedoms won: afro-brazilians in postabolition São Paulo and Salvador. Nova Brunswick: Rutgers University Press, 1998.

BUTLER, Kim D. "A nova negritude no Brasil": movimentos pós-abolição no contexto da diáspora africana. In: DOMINGUES, Petrônio; GOMES, Flávio (orgs.). Experiências da emancipação: biografias, instituições e movimentos sociais no pós-abolição (1890-1980). São Paulo: Selo Negro, 2011, p. 137-56.

CAMARGO, Oswaldo de. Lino Guedes, seu tempo e seu perfil. São Paulo: Ciclo contínuo, 2016.

CHALHOUB, Sidney; PEREIRA, Leonardo Affonso de M. "Apresentação". In: CHALHOUB, Sidney; PEREIRA, Leonardo Affonso de M. (orgs.). A história contada: capítulos de história social da literatura no Brasil. Rio de Janeiro: Nova fronteira, 1998, p. 7.

CUTI (Luiz Silva). Literatura negro-brasileira. São Paulo: Selo Negro, 2010. DAMASCENO, Benedita. Poesia negra no modernismo brasileiro. Campinas: Pontes, 1988.

DOMINGUES, Petrônio. "Os jornais dos filhos e netos de escravos (18891930)". In: A nova abolição. São Paulo: Selo Negro, 2008, p. 19-58.

DOMINGUES, Petrônio. "Lino Guedes": de filho de ex-escravo à 'elite de cor'. Afro-Ásia, n. 41, 2010, p. 133-66.

DOMINGUES, Petrônio. "A aurora de um grande feito": a herma a Luiz Gama, Anos 90, v. 23, n. 43, 2016, p. 389-416.

DUARTE, Eduardo de Assis. "Por um conceito de literatura afrobrasileira". Revista de Crítica Literária Latinoamericana, Lima; Boston: ano XLI, n. 81, $1^{\circ}$. Semestre de 2015, p. 28-9; 41-2.

FERRARA, Miram. “A imprensa negra paulista (1915-1963)”. Antropologia, n. 23. São Paulo: FFLCH / USP, 1986.

FERREIRA, Maria Cláudia Cardoso. Representações sociais e práticas políticas do movimento negro paulistano: as trajetórias de Correia Leite e Veiga dos Santos (1928-1937). Dissertação (mestrado em História). Rio de Janeiro: Instituto de Filosofia e Ciências Humanas /UERJ, 2005.

FIGUEIREDO, Maria do Carmo Lanna; FONSECA, Maria Nazareth Soares (orgs.). Poéticas afro-brasileiras. Belo Horizonte: Mazza; PUC Minas, 2002.

FONSECA, Maria Nazareth Soares. "Literatura negra: os sentidos e as ramificações". In: DUARTE, Eduardo de Assis; FONSECA, Maria Nazareth Soares (orgs.). Literatura e afrodescendência no Brasil: antologia crítica. Belo Horizonte: UFMG; Brasília: SEPPIR, 2014 (2a ed.), v. 4, p. 24577.

FRANCISCO, Flavio Thales Ribeiro. Fronteiras em definição: identidades negras e imagens dos Estados Unidos e da África no jornal O Clarim da Alvorada (1924-1932). São Paulo: Alameda, 2013. 
GOMES, Heloísa Toller. "Lino Guedes". In: DUARTE, Eduardo de Assis (org.). Literatura e afrodescendência no Brasil: ontologia crítica. Belo Horizonte: Ed. UFMG, v. 1, 2011, p. 349-63.

GOMES, Tiago de Melo. Um espelho no palco: identidades sociais e massificação da cultura no teatro de revista dos anos 1920. Campinas: Unicamp, 2004.

LEITE, José Correia. E disse o velho militante José Correia Leite: depoimentos e artigos. Organizado por Cuti. São Paulo: Secretaria Municipal da Cultura, 1992.

MACIEL, Cleber da Silva. Discriminações raciais: negros em Campinas (1888-1926). Campinas: CMU /Unicamp, 1997 (2a ed.), p. 96-102.

MELLO, Marina Pereira de Almeida. O resurgir das cinzas: negros paulistanos no pós-abolição. São Paulo: Annablume, 2014.

MELLO, Marina Pereira de Almeida. Não somos africanos, somos brasileiros: identidade nos jornais do povo negro e dos imigrantes. São Paulo: Annablume, 2014.

MITCHELL, Michael. "Racial identity and political vision in the Black Press of São Paulo, Brazil, 1930-1947". Contributions in Black Studies: A Journal of African and AfroAmerican Studies, v. 9-10, 1991-1992, p. 17-29. MIRANDA, Rodrigo. Um caminho de suor e letras: a militância negra em Campinas e a construção de uma comunidade imaginada nas páginas do Getulino (Campinas, 1923-1926). Dissertação de mestrado. Campinas: Unicamp, 2005.

MOISÉS, Massaud. A criação literária. São Paulo: Melhoramentos, 1968, p. 81-2.

MOREIRA, Renato Jardim. Movimentos sociais no meio negro. São Paulo, mimeo., s/d.

PINTO, Ana Flávia Magalhães. Escritos de liberdade: literatos negros, racismo e cidadania no Brasil Oitocentista. Campinas: Unicamp, 2018.

PINTO, Regina Pahim. O movimento negro em São Paulo: luta e identidade. Ponta Grossa: Ed. UEPG; São Paulo: Fundação Carlos Chagas, 2013.

PIRES, Antônio Liberac Cardoso Simões. As associações de homens de cor e a imprensa negra paulista. Belo Horizonte: Daliana - MEC /SESU /Secad; Neab /UFT, 2006.

PROENÇA FILHO, Domício. "O negro na literatura brasileira". Boletim Bibliográfico Biblioteca Mário de Andrade, v. 49, n. 1/4, 1988, p. 77-109.

REIS, Carlos Antonio dos. A África impressa: identidades e representações da África na imprensa negra paulista (1916-1978). Tese de doutorado. Franca: FCHS /UNESP, 2016.

REIS, Ruan Levy Andrade. Letras de fogo, barreiras de lenha: a produção intelectual negra paulista em movimento (1915-1931). Dissertação (mestrado em História). São Paulo: Universidade de São Paulo, 2017. RUIZ, Roberto. Aracy Cortes: linda flor. Rio de Janeiro: Funarte, 1984. 
SANTOS, Rael Fiszon Eugenio dos. A África na imprensa negra paulista (1923-1937). Dissertação (mestrado em História). Niterói: Universidade Federal Fluminense, 2012.

SCHWARCZ, Lilia M. O espetáculo das raças: cientistas, instituições e questão racial no Brasil. São Paulo: Companhia das letras, 1993.

SEIGEL, Micol. Uneven encounters: making race and nation in Brazil and The United States. Durham: Duke University Press, 2009.

SEVCENKO, Nicolau. Literatura como missão: tensões sociais e criação cultural na primeira república. São Paulo: Brasiliense, 1999 (4 ed.), p. 20. SILVA, José Carlos Gomes da. "Negros em São Paulo": espaço público, imagem e cidadania. In: NIEMEYER, Ana Maria de; GODÓI, Emília Pietrafesa de (orgs.). Além dos territórios: para um diálogo entre a etnologia indígena, os estudos rurais e os estudos urbanos. Campinas: Mercado Aberto, 1998, p. 65-96.

SILVA, Mário Augusto Medeiros da. "Rastros do Cisne Preto": Lino Guedes, um escritor negro pelos jornais (1913-1969), Estudos Históricos, Rio de Janeiro, v. 30, n. 62, 2017, p. 597-622.

Petrônio Domingues doutorou-se em História pela Faculdade de Filosofia, Letras e Ciências Humanas da Universidade de São Paulo. É professor da Universidade Federal de Sergipe (UFS) e bolsista de produtividade em pesquisa (CNPq). Contato: pjdomingues@yahoo.com.br

ORCiD: https:// orcid.org/0000-0002-0116-5064

Ruan Levy Andrade Reis é mestre em História pela Faculdade de Filosofia, Letras e Ciências Humanas da Universidade de São Paulo. Contato: ruanlevyreis@gmail.com

ORCiD: https:// orcid.org/0000-0002-1501-1728 